\title{
Thrombolysis-related intracerebral hemorrhage and cerebral amyloid angiopathy: accumulating evidence
}

\author{
Andreas Charidimou ${ }^{1}$, James A. R. Nicoll ${ }^{2}$ and Mark O. McCarron ${ }^{3 *}$ \\ ${ }^{1}$ Department of Neurology, Massachussetts General Hospital, Boston, MA, USA, ${ }^{2}$ Department of Neuropathology, University \\ of Southampton, Southampton, UK, ${ }^{3}$ Department of Neurology, Altnagelvin Hospital, Londonderry, UK
}

Keywords: cerebral amyloid angiopathy, intracerebral hemorrhage, thrombolysis

OPEN ACCESS

Edited by:

Anders Fogh Christensen,

University Hospital of Copenhagen,

Denmark

Reviewed by:

Martin Ebinger

Charité - Universitätsmedizin Berlin,

Germany

*Correspondence:

Mark O. McCarron

markmccarron@doctors.org.uk

Specialty section:

This article was submitted to Stroke, a section of the journal

Frontiers in Neurology

Received: 17 March 2015

Accepted: 23 April 2015

Published: 08 May 2015

Citation:

Charidimou A, Nicoll JAR and McCarron MO (2015)

Thrombolysis-related intracerebral hemorrhage and cerebral amyloid angiopathy: accumulating evidence.

Front. Neurol. 6:99.

doi: 10.3389/fneur.2015.00099
Intracerebral hemorrhage (ICH) is the most feared risk of systemic thrombolysis for ST-elevated myocardial infarction, pulmonary embolism, or acute ischemic stroke. Clinical, radiological, and pathological evidence suggests that cerebral small vessel disease and, in particular, cerebral amyloid angiopathy (CAA) may contribute to or in some cases directly underpin thrombolysis-related intracerebral hemorrhage (TICH) (1). Further developments, particularly in neuroimaging, have strengthened this hypothesis, hinting at the prospect of identifying biomarkers to measure TICH risk for individual patient groups. Emerging biomarkers for CAA such as lobar cerebral microbleeds (2) may become increasingly useful for outcome endpoints in clinical trials and patient risk stratification for TICH (3).

Thrombolysis-related intracerebral hemorrhage is a complex pathophysiological process. For ischemic stroke patients, a key issue is the location of TICH, i.e., hemorrhage into the area of ischemia vs. hemorrhage in a remote non-ischemic site (occurring in about $20 \%$ of patients with symptomatic TICH). Classification of TICH has traditionally focused on clinical and radiological features (4), with less emphasis on whether different mechanisms might be implicated in TICH in remote from or within the acute infarcted region (5) or whether pathological assessment has occurred.

Coregistered Pittsburgh compound B positron emission tomography (PiB-PET) imaging has revealed that spontaneous hemorrhage hotspots preferentially occur at locations with increased amyloid $\beta$-protein burden (6). In patients treated with recombinant tissue plasminogen activator (rt-PA) for acute ischemic stroke, cerebral amyloid $\beta$-protein (as detected with PiB-PET) retention was higher in patients with parenchymal hemorrhage compared to patients without (7). Although PiB-PET has somewhat poor spatial resolution and cannot reliably resolve parenchymal and cerebrovascular amyloid $\beta$-protein, the finding is probably one of the strongest pieces of radiological evidence implicating CAA in TICH. Matrix metalloproteinase 9, a zinc-dependent endopeptidase and a marker of hemorrhagic transformation after ischemic stroke, is released from neutrophil granules by rt-PA in humans (8). Amyloid $\beta$-protein can also release and activate MMP-9 from mouse endothelial cells (9), suggesting that convergent risk factors may lead to hemorrhage.

Cerebral microbleeds identified on MRI in a lobar distribution are considered a characteristic hemorrhagic marker of a vasculopathy related to CAA (2). It has slowly emerged that multiple microbleeds might increase the risk of symptomatic ICH following thrombolysis treatment, a relationship which increases with increasing numbers of microbleeds $(10,11)$. In more recent studies with larger groups of ischemic stroke patients receiving intravenous thrombolysis in both European and Chinese populations, multiple cerebral microbleeds were more clearly associated with symptomatic and parenchymal hemorrhage, respectively $(12,13)$. Future study may provide insights into potential mechanisms, and meta-analyses may highlight the relative importance of lobar and non-lobar cerebral microbleeds in stratifying the intracerebral hemorrhagic risk from thrombolysis. 
In a review in 2004 (1), we identified 10 patients with pathological investigation of TICH, 7 of whom had evidence of CAA. All of these patients had been treated for acute myocardial infarction and nine of the patients had multiple hemorrhages in a lobar distribution. With an increasing emphasis on primary percutaneous intervention for ST-elevated myocardial infarction, it may not be surprising that no further TICH cases following thrombolysis for acute myocardial infarction have been reported. However, although thrombolysis rates have increased for acute ischemic stroke patients, in an updated systematic literature search, only two further autopsy TICH cases (multiple and both hemispheres) have been reported in the stroke literature, both of whom had CAA (14). The relative lack of human pathological studies compared to neuroimaging studies hampers further developments in this area. A pathological register

\section{References}

1. McCarron MO, Nicoll JA. Cerebral amyloid angiopathy and thrombolysisrelated intracerebral haemorrhage. Lancet Neurol (2004) 3:484-92. doi:10.1016/ S1474-4422(04)00825-7

2. Yates PA, Villemagne VL, Ellis KA, Desmond PM, Masters CL, Rowe CC. Cerebral microbleeds: a review of clinical, genetic, and neuroimaging associations. Front Neurol (2014) 4:205. doi:10.3389/fneur.2013.00205

3. Greenberg SM, Salman RA, Biessels GJ, van Buchem M, Cordonnier C, Lee JM, et al. Outcome markers for clinical trials in cerebral amyloid angiopathy. Lancet Neurol (2014) 13:419-28. doi:10.1016/S1474-4422(14)70003-1

4. Sussman ES, Connolly ES Jr. Hemorrhagic transformation: a review of the rate of hemorrhage in the major clinical trials of acute ischemic stroke. Front Neurol (2013) 4:69. doi:10.3389/fneur.2013.00069

5. Mazya MV, Ahmed N, Ford GA, Hobolm C, Mikulik R, Nunes AP, et al. Remote or extraischemic intracerebral hemorrhage-an uncommon complication of stroke thrombolysis: results from the safe implementation of treatments in stroke-international stroke thrombolysis register. Stroke (2014) 45:1657-63. doi:10.1161/STROKEAHA.114.004923

6. Gurol ME, Dierksen G, Betensky R, Gidicsin C, Halpin A, Becker A, et al. Predicting sites of new hemorrhage with amyloid imaging in cerebral amyloid angiopathy. Neurology (2012) 79:320-6. doi:10.1212/WNL.0b013e31826043a9

7. Ly JV, Rowe CC, Villemagne VL, Zavala JA, Ma H, O’Keefe G, et al. Cerebral beta-amyloid detected by Pittsburgh compound B positron emission topography predisposes to recombinant tissue plasminogen activator-related hemorrhage. Ann Neurol (2010) 68:959-62. doi:10.1002/ana.22072

8. Carbone F, Vuilleumier N, Bertolotto M, Burger F, Galan K, Roversi G. Treatment with recombinant tissue plasminogen activator (r-TPA) induces neutrophil degranulation in vitro via defined pathways. Vascul Pharmacol (2015) 64:16-27. doi:10.1016/j.vph.2014.11.007

9. Lee JM, Yin KJ, Hsin I, Chen S, Fryer JD, Holtzman DM, et al. Matrix metalloproteinase-9 and spontaneous hemorrhage in an animal model of attached to a clinical register would enhance our understanding of TICH, particularly in the older population with acute ischemic stroke.

The known predictors of clinically significant TICH currently include age, clinical stroke severity, high blood pressure, hyperglycemia, early CT ischemic changes, large baseline diffusion lesion volume, leukoaraiosis, and cerebral microbleeds on MRI; the evidence for a role of CAA in TICH continues to accumulate.

\section{Author Contributions}

AC conceived the idea and reviewed the literature and drafts of the paper. JN contributed to the writing, analyzed the literature, and reviewed drafts of the paper. MM wrote the first draft and reviewed drafts of the paper.

cerebral amyloid angiopathy. Ann Neurol (2003) 54:379-82. doi:10.1002/ana. 10671

10. Shoamanesh A, Kwok CS, Lim PA, Benavente OR. Postthrombolysis intracranial hemorrhage risk of cerebral microbleeds in acute stroke patients: a systematic review and meta-analysis. Int J Stroke (2013) 8:348-56. doi:10.1111/j. 1747-4949.2012.00869.x

11. Charidimou A, Kakar P, Fox Z, Werring DJ. Cerebral microbleeds and the risk of intracerebral haemorrhage after thrombolysis for acute ischaemic stroke: systematic review and meta-analysis. J Neurol Neurosurg Psychiatry (2013) 84:277-80. doi:10.1136/jnnp-2012-303379

12. Dannenberg S, Scheitz JF, Rozanski M, Erdur H, Brunecker P, Werring DJ, et al. Number of cerebral microbleeds and risk of intracerebral hemorrhage after intravenous thrombolysis. Stroke (2014) 45:2900-5. doi:10.1161/ STROKEAHA.114.006448

13. Yan S, Jin X, Zhang X, Zhang S, Liebeskind DS, Lou M. Extensive cerebral microbleeds predict parenchymal haemorrhage and poor outcome after intravenous thrombolysis. J Neurol Neurosurg Psychiatry (2015). doi:10.1136/ jnnp-2014-309857

14. Mattila OS, Sairanen T, Laakso E, Paetau A, Tanskanen M, Lindsberg PJ. Cerebral amyloid angiopathy related hemorrhage after stroke thrombolysis: case report and literature review. Neuropathology (2015) 35:70-4. doi:10.1111/ neup. 12152

Conflict of Interest Statement: The authors declare that the research was conducted in the absence of any commercial or financial relationships that could be construed as a potential conflict of interest.

Copyright (C) 2015 Charidimou, Nicoll and McCarron. This is an open-access article distributed under the terms of the Creative Commons Attribution License (CC BY). The use, distribution or reproduction in other forums is permitted, provided the original author(s) or licensor are credited and that the original publication in this journal is cited, in accordance with accepted academic practice. No use, distribution or reproduction is permitted which does not comply with these terms. 